\title{
Final year medical and social worker student's socio- political \& religious backgrounds compared to the general public: The person-in-the-professional
}

\author{
Colin Pritchard ${ }^{*}$ \\ Health \& Social Sciences, Bournemouth University, School of Medicine, University of Southampton, UK
}

\begin{abstract}
The caring professions of medicine and social work increasingly stress the need for an understanding of the background of services users to develop the necessary professional relationship and to be culturally sensitive. However, we could find no study that focused upon the individual professional's political values, in effect treating professionals as inter-changeable technicians. This study seeks to understand to what extent, final year medical and social work's student's, from two Southern English cities and two adjacent universities, religio-political beliefs vary with the general public whom they would serve. The confidential self-administered questionnaire provided two student's group value system, there were slight differences, more medical students from ethnic minority background and more female social workers, whilst more than half were 'agnostics', religious difference were related to student's ethnic background.

Ignoring age differences there were statistically significant differnces with the general populations results, based on Social Trends and 2019 General Election. Students were significantly less religious, more left of centre, more middle-class backgrounds than general population. Whilst being younger than those they would serve, was expected, the extent of the religio-policitcal and social class backgrounds suggest that it is the 'professionals' who are the 'minority' compared with those whom they would serve..
\end{abstract}

\section{Introduction}

The persistence of poor child health outcomes and socio-economic disadvantaged continues in the UK and across the Western world [13]. Whilst there is recognition that ethnic minorities are especially vulnerable [4-7] and the one pervading category, is to belong to the lower socio-economic class $[4,7,8]$.

This poses the question what must it feel like to belong to a disadvantaged group and can professionals such as physicians, social workers be culturally sensitive enough to understand their serviceusers situation?

Social Work has long prided itself on being culturally aware of the people it serves [9-11] based upon the core skill of establishing a professional relationship with service users $[12,13]$. However, the focus has been upon the client not the person-in- the-professional, that is the individual Social Worker's own politico-religious values. Whilst there are studies related to social policy and underlying political-ideology of the discipline [14-18], we could find none related to the individual Social Worker's political allegiance. The closest we could find were studies of Social Workers' personal situation in regard to multi-faith religious beliefs $[11,19,20]$.

This is similar to the situation for individual Doctors. In an examination of the medical data base MedLine, we found 2,747 concerned with physician-patient relationship but as with Social Work, the focus was predominately upon the patient's background and found no study that explored the individual physician's personal situation, their original social class or politico-religious beliefs, features that are at the heart of a person's cultural identity.
As with Social Work, the need for cultural competency of physicians is increasingly being recognised across the Western world [19-26].

One major survey of how UK Social Workers valued issues of religion. Whilst more than half their respondents thought it important BUT from an initial random sample of 5,500 there was only a $14 \%$ response rate (789), suggesting that those who responded would probably be more likely to have a religious orientation [19], but a possible minority amongst most social workers?

A key feature about the professional is their social class, as it has long been argued that 'social class' over-arches gender and ethnicity and how it might colour the professional's view of the pursuit of social justice $[27,28]$.

In regard to Doctors and social class, there appears to be limited cultural understanding and many physicians believe that they remain 'neutral' to the patient's Socio-Economic-Status (SES) so are in danger of failing to respect or adequately understand the patient's different socio-cultural ethos $[9,21,25,26]$.

Failure by professionals (physicians, Social Workers) to understand another's cultural diversity has been found to undermine the effectiveness and safety of their service across the professions [9,20,29-34].

${ }^{*}$ Correspondence to: Colin Pritchard, Research in Psychiatric Social Work, National Centre for Post-Qualifying Social Work \& Professional Practice; Health \& Social Sciences, Bournemouth University, School of Medicine, University of Southampton, UK, E-mail: CPritchard@bournemouth.ac.uk

Received: July 22, 2021; Accepted: August 12, 2021; Published: August 16, 2021 
Conversely, engaging users in a positive professional-patient communication, research has demonstrated measurable benefits for individual service-users and their families [9,29,33]. For example, using a Social Work approach in high tech medicine- neurosurgery, brought measurable benefits to clients, their families and the service and engaged relationships were the effective change element [29,35]. Whilst other Social Work research found positive outcomes centrally related to the ability to engage the service-users as the relationship is the basis of effectiveness in all the human-interactive services $[10,13,33][9,36,37]$.

The concept of 'culture' is complex but in simple terms culture can be thought of as the personal window upon the world, shaped by a set of beliefs, values and attitudes linked to individual and group attributes that created their sense of personal identity. Thus culture can be an attribute that narrows the person's view of others $[9,38]$.

A person's cultural attributes fall into a number of broad qualities: given, chosen, rejected and emergent qualities. For example given attributes include age, gender, family background - plus one's original social class, nationality and ethnicity; chosen attributes might include religious or political affiliation; rejected attributes might involve family values that a young person opposes during adolescence; and emergent attitudes can include those of university years and later professional identity. Furthermore, only a few cultural attributes are readily observable such as physical appearance and language, whereas it is suggested that the majority are hidden possibly even from the person themselves [24,30,32,37].

In Britain, the socio-economic class of a Doctor and Social; Worker is Class one, with the semi and unskilled workers are categorised as classes six and seven, what might be described as the traditional working class [38].

Differences in social class can lead to serious misjudgements between both patent/ client and the professional, as social-class is self-evidently often correlated with education, highlighted in a major systematic review that explored the 'social gradient in doctor-patient communication' [21,31-33]. Typically they ignored the idea that the professional's personal perspective may play any part in the dyad interaction.

Thus, a service-user tends to be seen as a passive recipient of the professional care offered, all of which is influenced by elements within their culture $[8,24,30,39]$ which requires the professional's selfmonitoring of their practice $[10,13,33,37,40]$.

In Social Work is the increasingly active involvement and feed-back from service users [41,42].

The virtual lack of anything in the literature about the professional's personal background, tacitly assumes that professionals are trained neutral inter-changeable people, uninvolved, detached, only focusing upon what the patients brings, is as if all professionals are seen as simple inter-changeable automata - which self-evidently cannot be true.

In regard to 'political' allegiance, it can be argued that the most recent General Election (2019) gives a broad indicator of current political support to be found in the General Public [43]. serve?

Therefore how might professionals differ from the public they

Hence this study of final year Medical and Social Worker's individual politico-religious and social class backgrounds. The focus is less upon any differences between the professionals but any substantial gaps between them and the general-public, whom they would serve.
There is one working null hypothesis that there will be no statistically significant differences between Medical and Social Work final year students and the general public's politico - religious allegiances.

\section{Method}

The study emerged out of a participatory medical student seminar, designed to explore the 'person in the professional' of those willing to anonymously share their demographics to be contrasted against their cities background and then fed back during the seminar. The extent of the differences surprised the students, so it was decided to undertake a more formal planned project with a new group of final year Medical and Social Work students from two adjacent Universities. A self-administered questionnaire was designed that sought to elicit professional's social class back grounds and their socio-religious perspectives, ensuring total anonymity of their answers. We gained ethics committee approval (xxxxx University Ethics Committee ID 4689) to approach the students, to take part in a seminar on 'the personin-the-professional' that they knew would be reported anonymously back separately to the groups. No individual could be identified from the questionnaire, only the 'group' results were discussed.

\section{Sources of data}

All respondents' demographic data came from the completed anonymous student questionnaire. Their social class origins were based upon their parent's occupation and they indicated any religious and/ or political affiliation. The questionnaires were destroyed after analysis.

The politico-religious data on cities' adult population $(>18)$ was obtained from the latest Social Trend (2020) data and the general public's demographics from the city archives [38]. This constituted people aged $>21$ years in two adjacent Southern English university cities. The general population's 'politics' were obtained from the cities' British General Election results [43].

It is recognised that the student groups themselves will have inherent differences reflecting the two disciplines' educational background, arts $\mathrm{v}$ sciences. Yet in the last analysis both Doctors and Social Workers are dealing with the totality of the human experience, which centres upon the service user-professional interaction and relationship.

The fact that the student groups would be expected to younger than general population was taken as a self-evident given.

Whilst the focus of the study is any differences between the 'professionals and general public, such difference and any between the students, were tested by Chi Square test, with a one in twenty probability ( $p<0.05$ ) being considered statistically significant.

\section{Results}

\section{Medical v social work students}

There were $46 \mathrm{Medical}$ and 48 Social Work final year students. There were $48 \%$ female Medical students to $90 \%$ female Social Work students $(\mathrm{p}<0.001)$ and Medical students were younger, 65\% being under 23year to $46 \%$ Social Workers and fewer mature ( $>30$ years) students $9 \%$ to $28 \%$ Social Worker $(\mathrm{p}<0.001)$.

In terms of Social Class, there was no significant statistical difference between being middle class (Classes 1\& 2) of Medical to Social Work students $80 \%$ to $63 \%$ and working class (classes $6 \& 7$ ) $7 \%$ to $13 \%$ between the two groups. 
In regard to religious affiliation $54 \%$ of Medical students to $56 \%$ of Social Workers declared themselves as agnostics or atheist. The student's with religious affiliations mainly reflected their ethnic backgrounds, with $24 \%$ and $40 \%$ Medical and Social Work were Christian, whereas the other Medical students belonged to the Hindu and Islamic faiths.

The Political value systems of the two professional groups was interesting, taking a simple dichotomy of progressive affiliation then there were no significant differences between them, $74 \%$ of Medical to $87 \%$ of Social Workers, voted for left-of-centre parties i.e. Green, Labour or Liberal Democrats.

However, when examining the five possible affiliations, $26 \%$ to $13 \%$ of Medical to Social Work students supported Conservatism, to $22 \%$ and $48 \%$, so on this break-down the Social Workers were more progressive, the biggest difference was the groups' support for the Liberal-Democrats $41 \%$ of Medics to $21 \%$ of Social Workers.

\section{Differing cultures: The professionals v- General public}

There were no significant differences in the demographic patterns of the two cities' adults compared to the South West Region averages.

In regard to Gender, whilst medical students were not significantly different from their city males $52 \%$ to $49 \%$, the Social Workers, were predominately female $(\mathrm{p}<0.001)$. As would be expected the 'professionals' had a markedly different Age pattern to the general population $(\mathrm{p}<0.001)$. This has especially important features in regard to communication and understanding between professionals and service users, for example more than two-thirds the population were born the pre-digital age, and many service users would be as old as the professionals' parents or grand-parents. Students might take this for granted but those of us who have been 'users' often notice.

\section{Ethnicity}

Again, as might be expected there were more students from an ethnic minority, than in the Southern cities' general population. This matches current UK domiciled university ethnic minority students, are over-represented, more than double their presence in the general population; $29 \%$ to $14 \%$ [44].

\section{Social class}

By definition, all respondents are currently Middle Class (Class One). In regard to their social class origins, $80 \%$ of the Medics and $63 \%$ of Social; Workers came from the middle class compared to $42 \%$ of the general population.

Religious affiliation of respondents was also markedly different from the general population, $54 \%$ and $56 \%$ declaring themselves atheist/ agnostic to the cities' $40 \%$; and even the proportion of students being 'Christian' $24 \%$ and $40 \%$, is significantly different from the $52 \%$ of the general population $(\mathrm{p}<0.002)$.

\section{Political orientation}

The student groups were significantly more left of centre than the general population of the two cities. Medical and Social Worker respondents supported progressive parties $74 \%$ and $87 \%$, compared to the $38 \%$ and $49 \%$ of the cities $(\mathrm{p}<0.001)$. In the 2019 general election the cities voted $40 \%$ and $49 \%$ Conservative, compared to the Medical and Social Work respondents $26 \%$ and $13 \%$ respectively $(\mathrm{p}<0.001)$.

So, looking at these results from the average service-users perspectives, what might they see / feel?
Their 'average' Medical and Social; Work professional would be half their age; more likely to be a person from a middle class background and proportionately be more often to be non-believers and having a different political world view. More important, coming from a very different type of family background, the professionals are proportionally less likely to have experienced the psycho-socio-economic distress of many of their service users.

\section{Discussion}

\section{Main findings}

We can reject the null-hypothesis as there were significant difference between professionals and general population in all religiosocio-economic domains. For us, the biggest difference was between the professionals' middleclass educated backgrounds and the general public. Whilst the link between relative poverty and poorer health and social outcomes continues to be a relevant factor for both Medicine and Social; Work in all Western countries $[8,27,28,39,45-50]$.

The second major finding is to appreciate that both Medical and Social Work professionals will have a largely different world view than at least half the people they serve.

When set out like this at the feed-back sessions both student groups expressed surprise at the extent of the difference. The question then is, do these differences matter?

We think it does. First is the issue of inter-service-user-professional communication and a potential clash of values between themselves and their clients/ patients, where it is not just a difference of a knowledge base but more about values and life experiences.

We professionals are not psychosocially inter-changeable units/ widgets as consciously or otherwise, we will inevitably bring our own personal value systems to work.

It is suggested if young professionals consider these finding they will find a paradoxical confirmation from their own experience i.e. they find it easier to communicate with people similar to their own background. Thus from the perspective of the majority of clients and patients, it is the Medical and Social Work professionals who come from a different world to themselves, which can create real dangers at the service-user-professional interface [29,32-34,36]. This should be a major educational objective to help student professionals reach out and communicate with these families, as comparatively, many of us are from another 'culture'.

It is the professional's duty to communicate with the patient, not the other way round and we need to be able to lower the barriers that often daunt the people we serve.

The problem can be in the over-use of the defensive need to be professionally detached- yes but not too detached. Whereas a primary skill should be to recognise what the professional brings to the specific client/ patient- professional dialogue.

\section{Conclusion: Know thyself - Who is the minority}

Traditionally the professional's focus is supposed to be service-usercentred but we argue for the need to start from the classic position from the Oracle at Delphi of 'know thyself'.

It is argued that to understand another person from a different culture, social class or ethnic background, the practitioner needs to have active act of imagination otherwise everything is filtered through 
Pritchard C (2021) Final year medical and social worker student's socio-political \& religious backgrounds compared to the general public: The person-in-theprofessional

the professional's world view, reinforcing any stereotypes brought to the situation. Unless professional's challenge themselves they can continue to unaware of their de facto potential cultural and social class bias $[10,11,29,34,37]$. The only remedy for this is continued self-reflection on the cultural and political values of ourselves as agents of change.

We need to recognise and not fear the 'person-in-the-professional' perspective to the ensure we have the knowledge and skills to understand the culturally derived attitudes which could enrich the lives of the professionals as well being able to offer a more humanising service userspecific service. After all, in the last analysis it is we professionals who are the non-average 'minority' group'.

\section{References}

1. Anderson OS, McGuire JK (2019) Personal Faith and Professional Ethics: Best Practice with the Families of Sexual and Gender Minority Youths. Soc Work 64: 365372. [Crossref]

2. Arabsky S, Castro N, Murray M, Bisca I, Eva KE (20202) The Influence of Relationship-Centered Coaching on Physician Perceptions of Peer Review in the Context of Mandated Regulatory Practices. Acad Med p: S14-S19. [Crossref]

3. BBC (2019) General Election 2019.

4. Carpenter J, Shardlow SM, Patsios D, Wood M (2015) Developing the confidence and competence of newly qualified child and family Social; Workers in England: Outcomes of a national programme. Brit J Soc Work pp: 153-176.

5. Davies K, Gray M (2017) The place of service users expertise in evidenced-based practice. J Soc Work pp: 3-20.

6. D’Cruz H, Gillingham P (2016) Participatory research ideas and practice experience: Reflections and analysis. $J$ Soc Work 17: 434-452.

7. Decety J (2020) Empathy in Medicine: What It Is, and How Much We Really Need It. Am J Med 133: 561-566. [Crossref]

8. de Lima TJS, Pereira CR, Rosas Torres AR, Cunha de Souza LE, Albuquerque IM (2019) Black people are convicted more for being black than for being poor: The role of social norms and cultural prejudice on biased racial judgments. PLoS One 14: e0222874.

9. Epner DE, Baile WE (2012) Patient-centred care: The key to cultural competence. Ann Oncol pp: 33-42. [Crossref]

10. Foreman KJ, Marquez N, Dolgert A, Fukutaki K, Fullman N, et al. (2018) Forecasting life expectancy, years of life lost, and all-cause and cause-specific mortality for 250 causes of death: reference and alternative scenarios for 2016-40 for 195 countries and territories. Lancet 392: 2052-2090.

11. Furman LD, Benson PW, Grimwood C, Canda E (2004) Religion and spirituality ibn Social; Work education: A survey of UK Social; Workers. Brit J Soc Work 34: 767-792.

12. Gherardi S (2017) The Social; Worker's Dilemma: Empathy and Progress in the Trump Era. Soc Work 6: 285-295. [Crossref]

13. Green D, McDermott F (2010) Social; Work from the inside and between complex systems: Perspective of the person-in-environment: Need for sound understanding of social and political scene. Brit J Soc Work 40: 2414-2430.

14. Haider AH, Sexton J, Sriram N, Cooper LA, Cornwall EE, et al. (2011) Association of unconscious race and social class bias with vignette-based clinical assessments by medical students. JAMA 306: 942-951.

15. Harlow E, Berg E, Barry J, Chandler J (2013) Neoliberalism, managerialism and the reconfiguration of Social; Work in Sweden and the UK. Organisation 20: 534-550.

16. Hennessy R (2011) Relationship Skills in Social Work. London, Sage.

17. Hermann H, Manuel Trachsel, Biller-Andorno N (2015) Physicians' personal values in determining medical decision-making capacity: a survey study. J Med Ethics 41 : 739-744. [Crossref]

18. Janoff-Bulman R, Cames NC (2016) Social Justice and Social Order: Binding moralities across the political spectrum. Plos One 11: 1524-1547. [Crossref]

19. Jianbin X (2016) Pargament's theory of religious coping: Implication for spiritually sensitive Social; Work practice. Br J Soc Work 46:1394-1410. [Crossref]

20. Kannan VD, Veazie PJ (2014) Who avoids going to the Doctor and Why? Audience segmentation analysis for application of message development. Health Commun 25: 1-11. [Crossref]
21. Kingdon C, Roberts D, Turner MA, Storey C, Crossland N, et al. (2019) Inequalities and stillbirth in the UK: a meta-narrative review. BMJ Open 9: e029672.

22. Kørup AK, Søndergaard J, dePont Christensen R, Nielsen CT, Lucchetti G, et al. (2020) Religious Values in Clinical Practice are Here to Stay. J Relig Health 59: 188-194. [Crossref]

23. Mehlman MJ (2016) Who do you trust? Journal of Law and Medical Ethics 44: 589591

24. Minicuci N, Giorato C, Rocco I, Lloyd-Sherlock P, Avruscio G, et al. (2020) Survey of doctors' perception of professional values. PloS One 15: e244303. [Crossref]

25. Morely C, Ablett P (2016) A critical Social; Work response to wealth and inequality Social Alternatives 35: 240-258.

26. Papadaki V, Iliadou M, Karouzou E, Maragianni K, Pateraki O, et al. (2021) Support for Gay and Lesbian Rights Among Students of Helping Professions in Crete, Greece A Comparison between Social Work and Psychology Students. J Homosex 68: 934-956. [Crossref]

27. Rajmil L, Taylor-Robinson D, Gunnlaugsson G, Hjern A, Spencer N (2018) Trends in social determinants of child health and perinatal outcomes in European countries 2005-2015 by level of austerity imposed by governments: a repeat cross-sectional analysis of routinely available data. BMJ Open 8: e22932. [Crossref]

28. Riedl D, Schussler G (2017) The influence of the doctor-patient communication on health outcomes: A systematic review. Z Psychosom Med Psychother 3: 131-150. [Crossref]

29. Robieux L, Karsenti L, Pocard M, Flahault C (2018) Lets talk about empathy. Patient Educ Couns 101: 59-66. [Crossref]

30. Rodriquez JM, Geronimus AT, Bound J, Darling D (2015) Black lives matter: Differential mortality and the racial composition of the US electorate 1970-2004. Soc Sci Med 193: 136-137.

31. Ruch G, Turney D, Ward A (2010) Relationship-based Social; Work. Getting to the heart of practice. London, Jessica Kingsley.

32. Rudebeck CE (2019) Relationship based care - how general practice developed and why it is undermined within contemporary healthcare systems. Scand J Prim Health Care 37: 335-344. [Crossref]

33. Shaw J (2017) Introducing post-secular Social; Work: Towards a post-liberal ethics of care. Brit J Soc Work 47: 375-391.

34. Shay LA, Lafata E (2014) Understanding patient perceptions of shared decision making. Patient Educ Couns 96: 295-301. [Crossref]

35. Sidebotham P, Fraser J, Covington T, Freementle J, Pulikottil-Jacob R, et al. (2014) Understanding why children die in high-income countries. Lancet 384: 915-927. [Crossref]

36. Social trends (2020) Social Trends 2019. HMSO, London.

37. Strier R, Feldman G (2017) Social; Work's political passion: Policy, practice and neoliberalism. Brit J Soc Work 48: 751-756.

38. Uygur J, Judith Belle Brown JB, Carol Herbert C (2019) Understanding compassion in family medicine: a qualitative study. Br J Gen Pract 69: e208-e216. [Crossref]

39. Verlinde E, De Laender N, De Maesschalck S, Deveugele M, Williams S. (2012) The social gradient in doctor-patient communication. Int J Equity Health 12: 1-14 [Crossref]

40. Warren S, Deckert, JC (2019) Contemplative Practices for Self-Care in the Social Work Classroom. Soc Work 65: 11-20. [Crossref]

41. Watkins WJ, Kotecha SJ, Kotescha S (2016) All-cause mortality of low-birth weight infants in infancy, childhood and adolescence: Population study of England \& Wales. PlosMed

42. Wilkinson R, Pickett K (2009) The Spirit Level: Allen, London.

43. Hargreaves C, Tucker S, Hughes J, Hays R, Challis D (2019) Specialist healthcare services for UK care home residents: a latent class analysis. Prim Health Care Res Dev 16: e132.

44. van Hees SGM, van den Borne BHP, Menting J, Sattoe JNT (2019) Patterns of socia participation among older adults with disabilities and the relationship with well-being: A latent class analysis. Arch Gerontol Geriatr 86: 103933.

45. Hall J, Sammons P, Sylva K, Evangelou M, Eisenstadt N, et al. (2016) Disadvantaged families are at greatest risk from austerity cuts to children's centres. BMJ 352: i897. [Crossref] 
Pritchard C (2021) Final year medical and social worker student's socio-political \& religious backgrounds compared to the general public: The person-in-theprofessional

46. Tanaka H, Nusselder WJ, Bopp M, et al. Mortality inequalities by occupational class among men in Japan, South Korea and eight European countries: a national registerbased study, 1990-2015. J Epidemiol Community Health 73: 750-758. [Crossref]

47. Cummins I (2018) The Impact of Austerity on Mental Health Service Provision: A UK Perspective. Int J Environ Res Public Health p.15. [Crossref]
48. Arie S (2019) UK's "austerity experiment" has forced millions into poverty and homelessness, say UN rapporteur. BMJ 365: 12321.

49. Rustin B (1955) Speak Truth to Power: A Quaker Search for an Alternative to Violence, published by the American Friends Service Committee. New York.

50. Penn W (1693) Some fruits of solitude in reflections and maxims. Part 1: no.52. Oxford: Oxford University.

Copyright: $@ 2021$ Pritchard C. This is an open-access article distributed under the terms of the Creative Commons Attribution License, which permits unrestricted use, distribution, and reproduction in any medium, provided the original author and source are credited. 